\title{
Leasing instruments of high-rise construction financing
}

\author{
Olga Aleksandrova ${ }^{1,{ }^{*}}$, Elena Ivleva ${ }^{2}$, Viktoria Sukhacheva $^{2}$, and Anna Rumyantseva ${ }^{2}$ \\ ${ }^{1}$ Military Educational-Scientific Center of the Air Force of "The Air Force Academy named after \\ Professor N.E. Zhukovsky and Yu.A. Gagarin”, 1, Marshala Zhukova str., Syzran, Russia \\ ${ }^{2}$ Private Educational Institution "St. Petersburg University of Management Technologies and \\ Economics", 44, Lermontovsky Prospekt, St. Petersburg, Russia
}

\begin{abstract}
The leasing sector of the business economics is expanding. Leasing instruments for high-rise construction financing allow to determine the best business behaviour in the leasing economy sector, not only in the sphere of transactions with equipment and vehicles. Investments in high-rise construction have a multiplicative effect. It initiates an active search and leasing instruments use in the economic behaviour of construction organizations. The study of the high-rise construction sector in the structure of the leasing market participants significantly expands the leasing system framework. The scheme of internal and external leasing process factors influence on the result formation in the leasing sector of economy is offered.
\end{abstract}

\section{Introduction}

The replacement of fixed assets is required to ensure sustainable economic growth. There is a problem of investments accessibility for financing the enterprises of the real economy. Considering that investments in high-rise construction, along with investments in the development of the industrial sector and the transport system, have a multiplicative effect, the solution of this problem is also associated with the growth of the final economic effect (result).

The most effective way to finance a growing economy is leasing. The current policy of import substitution enables the leasing sector to supply equipment for the producing units retooling, which stabilizes both the leasing sector and the economy as a whole.

Today we can state: leasing financing is successfully developing and increasing the power. In 2016, the amount of new contracts increased by $39 \%$ and reached a volume of 1.2 tn rub. [6]. Leasing is gaining increasing recognition in the regions. In 2016, regional transactions increased by $33 \%$ and amounted to 375 bln. rub.; leasing transactions are becoming larger. The average transaction amount increased compared to 2015 from 6.7 to $8.2 \mathrm{mln}$. rub. The share of leasing business in GDP reached 1.2\% that corresponds to the precrisis level. Leasing business has a steady tendency to increase its portfolio, compared with investments in fixed assets, which have a negative dynamics (-3\%) according to the Ministry of Economic Development [12].

\footnotetext{
*Corresponding author: post_graduate@mail.ru
} 
Despite the positive dynamics in the leasing sector, there are bottlenecks; the share of bad debt is one of them [11]. In 2016, it was $10 \%$, which is $2 \%$ lower than the previous year. The result of debt reduction was achieved through the withdrawal of equipment from insolvent debtors that leads to new problems for the leasing company (loss of financial assets, deterioration in the quality of assets, the problem of the seized equipment sale, etc.). In 2016, the volume of restructured debt increased to $20 \%$ [13].

\section{Methodology and theory}

There is still no special regulation of the leasing services market. Leasing has a direct impact on investment and national wealth, which determines the importance of reform for economic development. By the end of 2017 it is expected to adopt a law on the regulation of leasing companies that should take effect next year. The Central Bank is ready to develop guidance on the methodology for calculating capital, industry standards of accounting that are associated with amendments to the law on leasing [8]. The main activities are designed to transform management standards in leasing, improve the risk management and operational environment of leasing companies, which will raise investor confidence and improve the business environment in the leasing sector. It is expected that the reform will positively affect the volume of the leasing market and will bring leasing to a new level of development. Full and transparent regulatory norms will improve the efficiency of the leasing sector and ensure economic mutual benefits for all participants of the leasing process [5].

The effectiveness of the leasing economy sector reform largely depends on the synchronization of innovations. A systematic approach when implementing reform measures will achieve the best result. Management in the leasing economy sector is advisable to consider on the basis of a systematic approach that allows to review the situation comprehensively, to study not only individual elements but their totality. The system approach allows to find the source of problems both inside the system and in the external environment. Existing links in the system allow to transfer the properties of an individual element entering the system to the rest of its elements. The effective functioning of the system depends on the effective interaction of its elements, which consists in achieving the stated goal and result, both of each element of the system, and of the system as a whole [4].

The main goal, which is set in the system design, is the resolution of emerging problems related to its functioning or the influence of the external environment on it.

The leasing process is supposed to be viewed as a set of economic entities engaged in a certain type of business and joined with transaction links. The communication of the participants is quite complex and constantly forms new relationships. Business in the leasing economy sector is characterized by a state of emergence, when the overall effect of the leasing process does not correspond to the sum of the effects of its participants [1].

The leasing process is based on the division of labor, which leads to the dispersal of entrepreneurial functions and the complication of the process itself. It is expressed in the autonomy of the leasing process participants, who are authorized to make decisions independently, carry out entrepreneurial activities within the established framework that affects the efficiency of not only individual participants, but also the entire leasing economy sector. To improve the performance of the leasing economy sector is possible when integrating the goals of the leasing process participants, taking into account the fact that the substantive side of the participants' activities does not change.

To implement the system approach in the management of the leasing economy sector, including the field of high-rise construction, it is necessary to clearly represent the elements of the system, the relationships between them, their goals, objectives and principles of operation [3]. Currently, the leasing system is formed spontaneously, but in the process of its functioning, in search of effective options for interaction between the leasing transaction 
participants, a new paradigm is created. The goal of building a leasing system is to increase the effectiveness of each participant of leasing process and leasing business in general, by reducing the risks and uncertainties of the process.

Leasing business is oriented towards providing services to economic entities and involves many participants to its implementation. Leasing business is defined as a set of independent organizations interacting with each other, engaged in various entrepreneurial activities, including leasing, investment, trade relations, and placed under the obligations for the purposeful use of financial resources for the acquisition of the leased asset with the aim of making a profit [3].

The system of leasing business is complex, because each participant is an independent economic unit engaged in its own kind of entrepreneurship; each has its own goals that can be contradictory, its tasks, and each one achieves them in different ways. A mismatch of interests can lead to devastating consequences. The defining condition for the leasing system development is the unity of business objectives. The actions of entrepreneurs are aimed at meeting market demand. The profit that entrepreneurs expect to receive from their activities is an indicator of the resource use effectiveness.

The leasing system is an economic system that has adaptive properties in the process of performing a complex of leasing operations in transport, industry and construction, which is formed from several subsystems with a high degree of interaction between themselves and the external environment [2].

Management performs various functions in the continuous process of entrepreneurial activities. We have identified the following functions in the process of managing leasing activities:

1. Organization of leasing process. Shows principles of the leasing process participants interaction as elements of the system and determines the order of their operation.

2. Planning and forecasting of the leasing process. Determines the sequence of actions to achieve the desired and possible development options. This function is based on increasing equity capital, building up the norm of profitability, coordinating the volume of operations.

3. Regulation. The measures that determine the leasing process framework due to compliance with the laws and regulations as a rule.

4. Motivation of activities. The basis is the argumentation in favor of a decision that motivates the leasing participants to certain actions to achieve the goal, both personal and general.

5. Stimulating the leasing business development. We have in mind the existence of reasons that would lead to actions resulting in the leasing economy sector development. External (macrolevel) reasons caused by long-term events and not dependent on the decision of the leasing transaction individual participant can be identified, as well as internal (microlevel) ones that have arisen inside the leasing system, i.e. between the participants as a result of their actions.

6. Accounting and control. It reflects the results of the leasing transaction participants activities in a documentary manner and verifies the correctness of the use of the relevant provisions and statutory acts provided for by law.

The leasing process management is connected with the final financial and economic result of the transaction sites activities, which depends on a variety of particular factors [1].

Defining the strategy for managing leasing business, it is necessary to strive to achieve the following goal: the leasing process implementation should be aimed not only at creating additional capital, but also at preserving the base capital of all leasing participants.

To make a decision in conditions of uncertainty, the following rules should be followed:

- not to risk more than own capital can allow, guided by the framework of the capital structure theory;

- always think about the chances and consequences of risk; 
- a positive decision is taken only in the absence of doubt;

- not to throw a whale to catch a sprat;

- always evaluate the options [9].

The effective functioning of the leasing sector largely depends on the environment in which the leasing process takes place. Carrying out a leasing deal, participants are exposed to both internal and external factors, which has a certain effect on the outcome of both the individual leasing transaction participants and the leasing economy sector.

We propose a scheme (Figure 1) of the influence of external and internal factors of each economic subject (participant) of the leasing process on the formation of the result in the leasing sector.

$B^{n . c}$ - the amount of effective demand.

$B^{h . m}$ - state of the scientific and technical products market.

$B^{\kappa}$ - growing competition.

$B^{p . l}$ - leasing development opportunities.

$B^{f . r}$ - the financial market state.

$B^{\kappa . n}$ - credit policy.

$B^{e . p}$ - economic and political situation in the country.

$B^{n . p}$ - legal regulation.

$B^{y \cdot u}$ - rate of inflation.

$B^{h . n}-$ tax policy.

$B^{u}$ - infrastructure development.

$P^{h . f}$ - availability of financial resources.

$P^{n . o}$ - the production equipment state.

$P^{n . n}$ - product parameters.

$P^{m . p}$ - methods of business regulation.

$P^{f . n}$ - financial potential of the company.

$P^{d . n}$ - business policy and management of the organization.

$P^{p \cdot p}$ - efficient allocation of resources. 


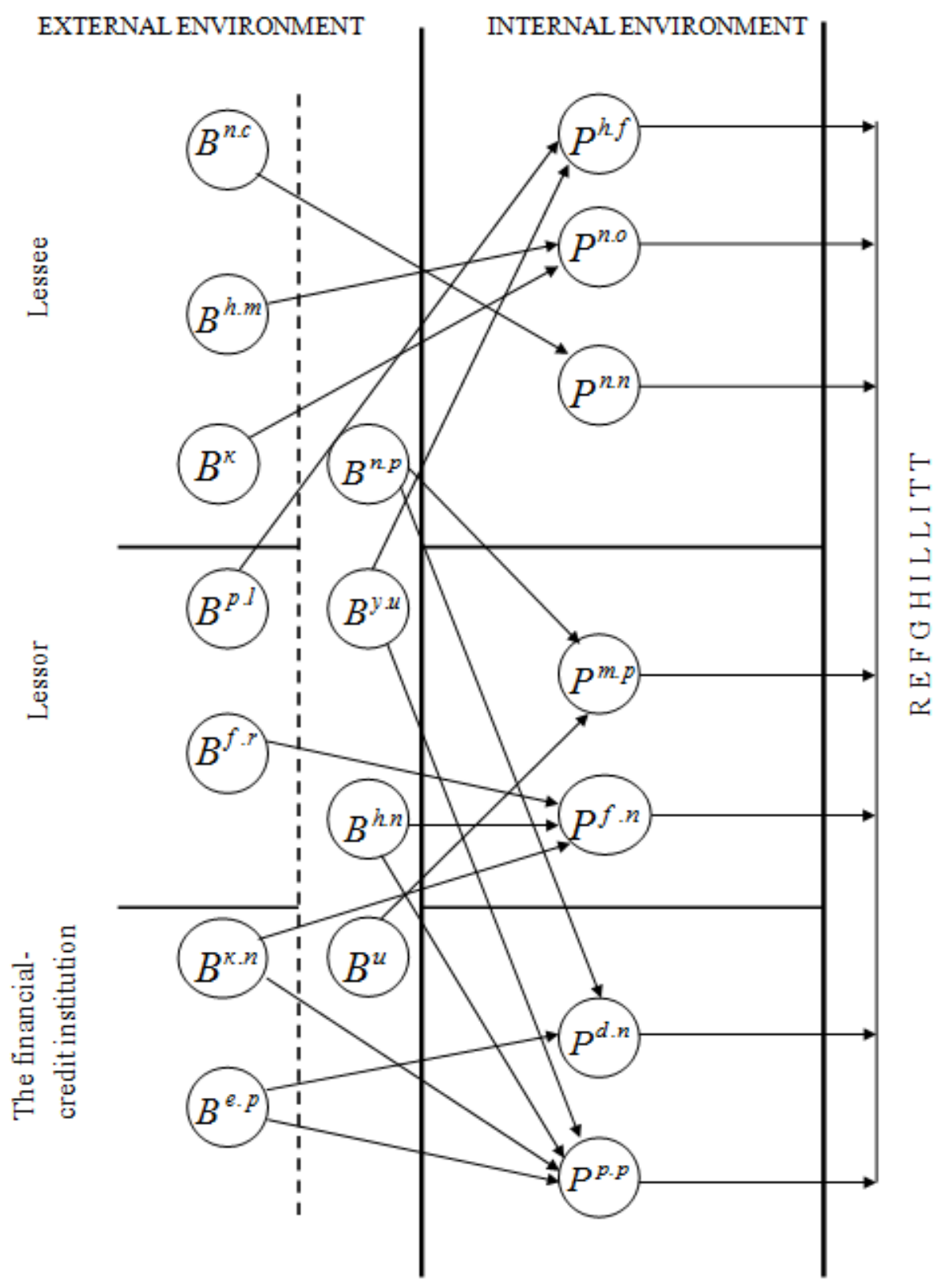

Fig. 1 Factors of external and internal environment of the leasing business participants, affecting the result.

Prepared by the authors.

The formation of internal factors of the leasing process participants and their financial results are influenced by external factors [15]. The leasing participants feel the influence of external factors as well as factors of an individual nature. The internal environment factors are determined by the entrepreneur on the basis of an external environment analysis and are used to establish the boundaries of the business structure functioning. Connections between the leasing system participants exist; they can be material (relations with respect to the leasing 
object), monetary (settlements between participants), informational (receipt, exchange of information). Internal links between the leasing participants have a stronger manifestation than external ones, they are of a cyclic nature, as the flows move progressively. The links between the leasing process participants can be direct, reverse, indirect.

The effectiveness of the leasing market functioning depends on the management system of both a separate leasing participant and the leasing process as a whole. Reducing the impact of external and internal factors to the leasing process functioning is aimed at solving two problems:

- ensuring of leasing business effective development;

- reduction of entrepreneurial activity participants risks [11].

To reduce financial losses, leasing companies are increasingly turning to risk management. The quality of risk management in the leasing market is low. Risk management is based on the lessee analysis, assessment of the subject of leasing and control over the process of transferring leased property. The advance amount is at the heart of reducing the possible risk. The leasing process participants need to know the actual cost of the risk, which is expressed in the actual loss of the lease participants or the costs of reducing, compensating for the losses that have occurred [10].

The leasing process participants act in concert in time, interact on a single vector, i.e. the effect caused by the coordinated actions in space and time of various economic entities leading to qualitative changes refers to the synergistic effect, which should lead to a qualitative breakthrough in the functioning of the system.

The leasing system is dynamic, which is confirmed by its change in time and space and is characterized by the following properties: stimulation, functionality; variability in time; existence in a changing environment.

The leasing system is exposed to the external environment, i.e. there are certain processes at the entrance to the system that affect it and lead to a change in the behavior of participants in the system. This property is called stimulation.

Functionality of the leasing system is considered as its behavior in the external environment and the dependence of processes on the output of the system. The functions of the leasing system are determined by the multiplicity of exits. The leasing participants use the system for their own purposes, evaluate its functions and arrange them in relation to their needs, as a result of which the functions are of importance: from the main to the secondary.

The main property of the dynamic system is its variability in time. As a rule, leasing deals are tied up not for one year, besides there is a tendency to lengthen the term of the deal. The terms of the leasing deal are the boundaries of the leasing system. Therefore, when organizing the leasing process, it is necessary to take into account possible changes during the validity of the leasing contract that affect the functioning of the leasing system and respond to them in a timely manner [3].

Changes that can occur at different rates affect the internal parameters of the system first of all. Positive changes cause the leasing system development. The emergence of a new participant in the leasing system leads to a change in the structure of the system, which affects its properties and leads to the growth of the system. So consideration of construction in the structure of the leasing market participants essentially expands the scope of the system.

Discussion. Financing leasing activities in the field of high-rise construction, studying the best economic practices in this area expands the scope of research on leasing activities. A special direction in this sphere was identified by V. Gazman - securitization of leasing assets in the conditions of reducing the volume of leasing financing by banks and complicating the conditions for crediting lessors [7].

The system exists in a continuously changing environment, which leads to a change in the system itself. To survive in such conditions, the system must adapt to external changes. Internal changes must be more active than external ones. And here it is necessary to compare 
the rate of change within the system with the rate of change in the external environment. In the leasing system, the rate of internal changes should be higher than the rate of external changes, which will reduce their negative development and increase the adaptability of the system.

The processes at the entrance to the leasing system have a stimulating character when it is organized and developed. They facilitate the integration of economic entities into a system on the basis of a leasing agreement. Most of the movement occurs within the system itself between its participants.

The greater the dynamic complexity of the system, the longer it takes for the signal to pass through the structure. One delay can lead to a significant delay in the signal [8]. Therefore, in order to change the situation in the right direction, it is necessary to take into account the discrepancies in the time of receipt of the signal and the result. To be able to change the situation, it is necessary to clearly understand the processes occurring in the leasing system.

The system growth and development lead to the emergence of new links between the elements. Additional relationships are formed as a result of the appearance of new elements in the system. Such connections can grow exponentially, i.e. each subsequent element increases the number of links to a greater extent than the previous one [8]. The appearance of a new system member leads to a change in the requirements for the final state of the system, which is not compatible with the previous one.

\section{The conclusion}

The connection between the elements (participants) of the system forms the system structure and serves as a guarantee of its stability. When the stability of the leasing system is violated, there are divergent processes that cannot be controlled and lead to the disintegration of the system.

Any system has a growth limit. When the optimal value is reached, when the system functions with maximum efficiency, the subsequent growth can lead to a decrease in efficiency. An uneven load of the system participants can provoke the occurrence of such a situation. At the point of effective functioning, it is necessary to determine the limitations the system can meet and take measures to avoid the growth limit. The applied system approach to the leasing process makes it possible to consider the management of interrelated and interdependent participants, which influence the efficiency of leasing business in the field of high-rise construction.

\section{References}

1. O. Alexandrova, O. Burgonov, E. Ivleva, Leasing tools of business economics. Russian scientific journal. Economics and management 5, 45-48 (2016)

2. Alexandrova O., Ivleva E., N. Shashina, Leasing mechanisms of business economics. Coll. of scient. papers of II International Research and Practical Conference Modernization of the Russian economy. Forecasts and Reality, 14-19 (2016)

3. O. Alexandrova, O. Burgonov, E. Ivleva, N. Shashina, Management of developing the leasing sector of entrepreneurial economy. Procedia Engineering 165, 980 - 989 (2016)

4. O. Aleksandrova, E. Ivleva, A. Kirdyashkin, N. Shashina, Infrastructural development factors of leasing entrepreneurship in real sector of economy. IOP Conf. Series: Earth and Environmental Science, 90 (2017) 
5. O. Adamchuk, The Central Bank mitigated the reform of leasing. Newspaper Vedomosti, (2017)

6. R. Bulatov, Leasing in Russia: restoration after stress. Leasing Revue 3, 2-15 (2017)

7. V. Gazman, Overcoming of stereotypes in leasing. Questions of economy 2, 136 (2017)

8. I. Drogobytsky, System analysis in the economy. $2^{\text {nd }}$ ed. UNITY-DANA Publ., 423 (2011)

9. S. Moiseev, Reform in leasing: how to fix an important mechanism for the economy. RBC, 79 (2017)

10. A. Shapkin, V.Shapkin, Theory of risk and modeling of risk situations: Textbook. Moscow, Dashkov and K Publ., 880 (2005)

11. D. Shperber, Organization of the leasing company management. Leasing business technology 3, 7-12 (2017)

12. The first leasing broker [Electronic source]. Available at: http://1lizing.ru (accessed 15.10.2017)

13. Federal Service of State Statistics. Available at: http://www.gks.ru/free_doc/doc_2015/invest.pdf (accessed 15.10.2017)

14. "Expert" Rating Agency. Available at: http://static2.banki.ru/ugc/4f/c4/05/59/Rynok_lizinga_po_itogam_2016_goda.pdf (accessed 22.10.2017)

15. A.Rumyantseva, Problems of financing the activities of small enterprises. Transactions of St. Petersburg University of Management Technologies and Economics 2, 41-52 (2015) 